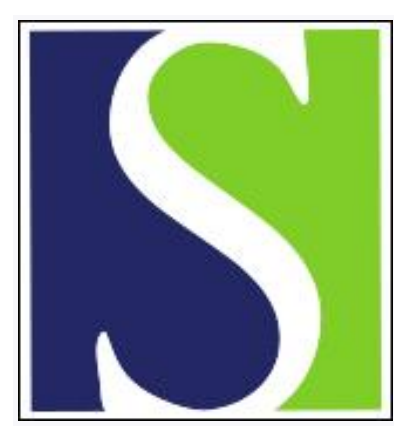

Scand J Work Environ Health 1997;23(3):206-213

https://doi.org/10.5271/sjweh.200

Issue date: Jun 1997

Are deficits in the equilibrium system relevant to the clinical investigation of solvent-induced neurotoxicity?

by Niklasson M, Möller C, Ödkvist LM, Ekberg K, Flodin U, Dige N, Sköldestig $\AA$

Key terms: chronic toxic encephalopathy; dynamic posturography; optoocular motor system; psychoorganic syndrome; saccade; smooth pursuit; solvent; vestibuloocular motor system; visual suppression

This article in PubMed: www.ncbi.nlm.nih.gov/pubmed/9243731 


\title{
Are deficits in the equilibrium system relevant to the clinical investigation of solvent-induced neurotoxicity?
}

\author{
by Magnus Niklasson, PhD, ${ }^{1}$ Claes Möller, PhD, ${ }^{1}$ Lars M Ödkvist, PhD, ${ }^{1}$ Kerstin Ekberg, PhD, ${ }^{2}$ \\ Ulf Flodin, PhD, ${ }^{2}$ Niels Dige, MSc, ${ }^{2}$ Åsa Sköldestig, $B S c^{2}$
}

\begin{abstract}
Niklasson M, Möller C, Ödkvist LM, Ekberg K, Flodin U, Dige N, Sköldestig A. Are deficits in the equilibrium system relevant to the clinical investigation of solvent-induced neurotoxicity? Scand $J$ Work Environ Health 1997;23(3):206-13.
\end{abstract}

\begin{abstract}
Objectives The diagnosis of solvent-induced chronic toxic encephalopathy is commonly based on case histories of exposure to solvents, symptoms, and deficits on psychometric tests. It has previously been demonstrated that long-term solvent-exposed workers have disturbances of the equilibrium system. The correlation between these disturbances and the diagnosis of chronic toxic encephalopathy has been analyzed in the present study.

Materials and methods Sixty men, consecutively admitted due to the suspicion of this syndrome, were investigated and classified into 3 groups - solvent-induced chronic toxic encephalopathy, incipient chronic toxic encephalopathy and nonchronic toxic encephalopathy. They were all examined using an otoneurological test battery, including analysis of saccades, smooth pursuit, visual suppression of the vestibular ocular reflex, and dynamic posturography.

Results Compared with healthy referents several of the subjects, even in the nonchronic toxic encephalopathy group, showed a reduced visual suppression ability, a prolonged latency of saccades, and pathological posturographic results. Some otoneurological tests correlated with the duration of exposure and the results of psychometric tests representing memory and perceptual skills. Nevertheless, there was no significant group correlation between the otoneurological findings and the diagnosis of chronic toxic encephalopathy.

Conclusion Disturbances revealed by an otoneurological investigation have so far not been considered in the diagnosis of chronic toxic encephalopathy. Our results indicate that an otoneurological test battery adds worthwhile information about lesions within the brainstem-cerebellar complex not revealed by a psychometric investigation.
\end{abstract}

Key terms chronic toxic encephalopathy, dynamic posturography, optoocular motor system, psychoorganic syndrome, saccades, smooth pursuit, solvents, vestibuloocular motor system, visual suppression.

Long-term occupational exposure to solvents may cause a neurotoxic syndrome commonly named chronic toxic encephalopathy. Symptoms related to chronic toxic encephalopathy are neurasthenic symptoms, changes in personality, tiredness, increased irritability, sleeping problems, and impairment in memory and learning skills. Other associated symptoms are feelings of unsteadiness and vertigo. The diagnosis of chronic toxic encephalopathy is usually based on symptoms, history of intensity, and duration of exposure to solvents, clinical neurological examination, and neuropsychological investigation (1).
So far neurophysiological tests have not usually been included in the clinical examination, even though pathological results have been reported to occur on a group level in electroencephalography, sensory evoked response, and the vestibulooptoocular motor system (1). Especially regarding the vestibulooptoocular motor system, there have been several reports demonstrating disturbances in the vestibular and optoocular motor reflex system, both in animals and in humans, during acute exposure and after long-term inhalation of different solvents (2-9). Investigation of the vestibular and optoocular motor reflex system may be a valuable comple-

1 Department of Otorhinolaryngology, Head and Neck Surgery, Faculty of Health Sciences, University Hospital, Linköping, Sweden.

2 Department of Occupational and Environmental Medicine, Faculty of Health Sciences, University Hospital, Linköping, Sweden.

Reprint requests to: Magnus Niklasson, Department of Otorhinolaryngology, Head and Neck Surgery, Faculty of Health Sciences, University Hospital, S-581 85 Linköping, Sweden. 
ment to the traditional clinical investigation used in the diagnosis of chronic toxic encephalopathy.

The aim of the present investigation was (i) to confirm previous suggestions and findings on disturbances of the central vestibular system in long-term exposure to solvents and (ii) to evaluate whether such disturbances, revealed by an otoneurological test battery, are related to the diagnosis of chronic toxic encephalopathy according to the aforementioned criteria.

\section{Description of groups}

Solvent group. Male workers in the age range of 26-65 (mean 48, SD 10) years and admitted between 1992 and 1994 from industrial health care units or regional social insurance offices because of psychiatric or neurological symptoms after exposure to organic solvents were consecutively included in the study. The investigation was continued until each of 3 severity categories in the final clinical diagnosis included approximately 20 workers. Subjects with other significant disorders of the central nervous system were excluded from the study. One subject with previous meningitis without sequelae, 1 subject with diabetes, and 1 subject with commotio cerebri without sequelae were included. Twenty-two of the 60 workers included were smokers and 2 consumed more than $37 \mathrm{cl}$ of strong spirits per week (no one was considered to abuse the use of alcohol). Prior to the investigation 16 subjects had been free of solvent exposure for 1 3 weeks, 10 subjects had not been exposed for 1 6 months, and for 34 subjects exposure had not taken place for $1-20$ years. The total duration of exposure ranged from 4 to 45 (mean 19, SD 10) years. Four major occupational groups were represented among the exposed workers ( 7 repairmen, 11 house painters, 19 spray painters, and 6 printers). Other categories included industrial workers (paint, degreaser, and plastic and petroleum product workers), car mechanics, and floor layers. The most common solvents involved were white spirits, thinner, toluene, and xylene ( $78 \%$ of all solvents). All subjects underwent a clinical examination at the occupational medicine clinic, and the general vestibular and special otoneurological tests were carried out at the otorhinolaryngology clinic.

Reference group. Twenty-seven industrial workers in the age range of $30-66$ (mean 45, SD 11) years and free of exposure to solvents were used as the reference group. None of the men had any history of central nervous disturbances. Eleven were smokers, and 26 used alcohol moderately (not exceeding $37 \mathrm{cl}$ of spirits per week). They had been used as a reference group in previous studies concerning solvent exposure $(6,7)$ and had all undergone a general vestibular and special otoneurological examination. Twenty-three workers [mean 51
(SD 11) years of age] underwent the dynamic posturographic tests 6 years after the other otoneurological tests.

\section{Methods}

\section{History, neuropsychiatric investigation and diagnosis}

Solvent exposure was assessed from a thorough interview to identify agent(s), duration, and intensity of exposure, and data on the monitored intensity of the solvent exposure at the workplace were collected, if available. Exposure intensity was primarily grouped into 6 categories from 0 (unexposed) to 5 (highest exposed). Degreasers, tank-cleaners, and floor layers are examples of the 5 th category. Construction painters and spray painters belonged to category 4 , unless they had consequently used respirators. If so, they belonged to category 3 , together with printers, repairmen, and industrial cleaners. Printers at especially well ventilated shops, aircraft mechanics, and artistic painters are examples of occupations in category 2. No subjects of categories 0 and 1 for example, kindergarten teachers, were included in this study. Subjects belonging to categories 4 and 5 were merged into a high-exposure group $[\mathrm{N}=36$, mean age 50 (SD 9) years], whereas exposure categories 2 and 3 were combined into a low-intensity group $[\mathrm{N}=24$, mean age 44 (SD 10) years]. The duration of exposure was classified into the 3 groups of $4-10,11-20$, and $21-$ 45 years of exposure. (For the mean age of the groups see figure 1.)

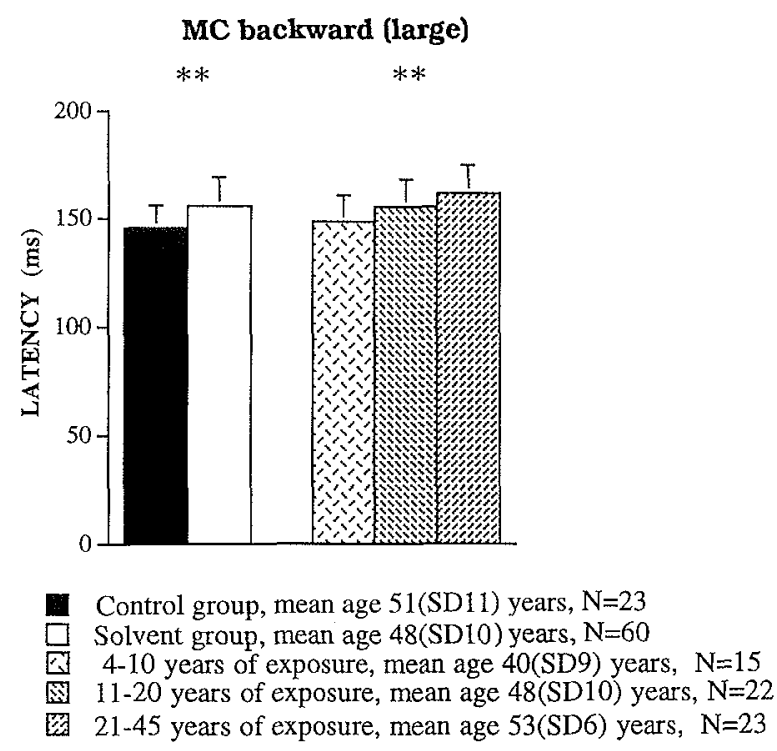

Figure 1. Dynamic posturography: mean latency of reaction time (ms) $+1 S D$ of backward large movements of the platform. (Reference and solvent groups on the left and solvent group split into groups representing different durations of exposure on the right; $M C=$ movement coordination; ${ }^{* *} P \leq 0.01$ ) 
The patients answered a validated questionnaire (1) on their symptoms, including fatigue, deterioration of memory, personality changes of aggressive or depressive type, and frequency of headache and sexual activity. A psychometric examination was performed of all the patients according to the TUFF battery (10). It included tests measuring cognitive functions, perceptual speed and accuracy, psychomotor speed, and memory and learning abilities $(10,11)$. The results of the tests with known sensitiveness for chronic toxic encephalopathy were classified into 4 groups (no, mild, moderate, or severe impairment). For the diagnosis of chronic toxic encephalopathy, the following requirements had to be met: (i) relevant symptoms and presence of pathological findings in the psychometric functions tests, (ii) a duration of exposure of at least 7 years and considerable intensity of exposure. For incipient chronic toxic encephalopathy no clearly pathological results were present in the psychometric examination, but the symptoms of the subjects were essentially the same as for manifest chronic toxic encephalopathy. A minimum exposure of 5 years was compatible with this diagnosis, as was a considerable intensity of exposure. For the nonchronic toxic encephalopathy group only vague and inadequate symptoms but no functional impairment in the psychometric examinations was present (12). The aforementioned test data were unknown to the investigators at the otorhinolaryngology clinic until all 60 subjects had participated in the otoneurological tests.

\section{General vestibular tests}

All the subjects (except 1 referent) participated in the tests routinely performed when vertigo and balance disorders are evaluated (table 1). The tests generated no numeric values but assessed the occurrence or nonoccurrence of different phenomena.

\section{Special otoneurological tests}

Saccade test. Fast voluntary eye movements were analyzed in the saccade test. The subject looked at 2 randomly alternating light-emitting diodes 20 degrees apart.

Table 1. Individuals with pathology in the general vestibular tests.

\begin{tabular}{lcc}
\hline Pathological finding & $\begin{array}{c}\text { Solvent-exposed } \\
\text { group } \\
(\mathbb{N}=60)\end{array}$ & $\begin{array}{c}\text { Reference } \\
\text { group } \\
(\mathbb{N}=26)\end{array}$ \\
\hline Caloric hyperreactivity & 17 & 1 \\
Caloric hyporeactivity & 1 & 1 \\
Caloric asymmetry & 3 & 2 \\
Caloric visual suppression & 5 & 0 \\
Spontaneous nystagmus & 3 & 2 \\
Positional nystagmus & 22 & 10 \\
Saccadic accuracy & 2 & 0 \\
Square waves & 22 & 1 \\
Gaze nystagmus & 3 & 0 \\
\hline
\end{tabular}

The latency (in milliseconds), accuracy, and maximum velocity (in degrees per second) were calculated (6).

Smooth pursuit tests. The ability of the subject to follow a moving object with his gaze was tested. A laser dot in front of the subject moved in sinusoidal frequency sweeps at $0.2-2.0 \mathrm{~Hz}$ with maximum velocities of 20 degrees/s (smooth pursuit test 50 ) and 40 degrees/s (smooth pursuit test 51) or in a pseudorandomized pattern at $0.2-2.0 \mathrm{~Hz}$ with a maximum velocity of $40 \mathrm{de}-$ grees/s (smooth pursuit test 56). Gain was calculated as the ratio between eye velocity and target velocity as a function of frequency (6).

Visual suppression tests. The ability to suppress eye movements, elicited by the vestibuloocular reflex, was tested. The subject was placed in a rotatory chair and instructed to fixate on a laser dot on a frame mechanically fixed to the chair. The movement patterns were sinusoidal frequency sweeps at $0.25-3.25 \mathrm{~Hz}$ (visual suppression test 30) and pseudorandomized oscillations at $0.25-3.75 \mathrm{~Hz}$ (visual suppression test 35 ) with a maximum velocity of 65 degrees/s. Gain was calculated as the ratio between the eye velocity and target velocity as a function of frequency. Low gain values indicated good visual suppression ability (6).

Dynamic posturography (body sway tests). The used body sway test (EquiTest ${ }^{\circledR}$ ) measures postural stability. It comprises 2 main parts. In the sensory organization tests the central integration of the vestibular, visual, and somatosensory inflow is evaluated. The movement coordination tests add information of the afferent-efferent regulation of postural control. In the sensory organization part of the test the subject stands on a platform enclosed by a visual surrounding. Both the platform and the visual surrounding can move as a result of anteroposterior sway of the subject and thus enable disturbances of the equilibrium. The platform recorded the vertical forces between the feet and ground due to the position of the swaying body. The sensory organization part was divided into 3 separate tests, each lasting $20 \mathrm{~s}$ and repeated 3 times. In these tests the support surface was always referenced to the patient's sway. The visual surrounding was either stable (sensory organization 4), not present (eyes closed) (sensory organization 5), or referenced to the patient's sway (sensory organization 6). The sway patterns were quantified on a scale of 100 to 0 , no sway of the platform being given a score of 100 , and sway of more than 12.5 degrees (or fall) being scored as zero.

In the movement coordination test, the platform made active movements in 4 separate tests, medium and large, forward and backward translations. These platform movements were performed with the eyes open to simu- 
late backward and forward falling. The latencies of the reaction time (in milliseconds) were calculated (13).

\section{Statistics}

The results of the special otoneurological tests were analyzed both for the individual subjects and as group comparisons.

Individual pathology. The values from each subject (both the exposed and reference subjects) were regarded as pathological if the values exceeded the means $\pm 2 \mathrm{SD}$ of the reference group. For the tests for which the values from several frequencies were analyzed (smooth pursuit tests and visual suppression tests), the results were regarded as pathological if the values of 4 or more of the frequencies exceeded the means $\pm 2 \mathrm{SD}$ of the reference group.

Comparison of groups using numeric values. The unpaired 2-tailed Student's t-test and factorial or repeated measures of variance (ANOVA) were used for the statistical analysis of the otoneurological tests in comparison with the subgroups as regards to the intensity and duration of exposure, psychometric evaluation, and diagnosis of chronic toxic encephalopathy.

The Spearman partial rank correlation coefficient was used in the analysis of associations between the otoneurological and psychometric tests. For the smooth pursuit tests and visual suppression tests, a significant correlation was judged to exist if at least 2 of the middle frequencies were significantly related to the psychometric tests. $\mathrm{P} \leq 0.05$ was considered significant for all the tests.

\section{Results}

The results of the general vestibular tests of the exposed subjects and the referents are presented in table 1 . Square waves (fast involuntary eye movements) and hyperreactivity during the caloric testing occurred much more frequently in the solvent-exposed group than in the reference group.

The results of the special otoneurological tests are summarized in table 2 . The latency of the voluntary

Table 2. Correlation of the otoneurologic test results between the referents and exposed workers and between the referents and subgroups according to clinical diagnosis. The significance values refer to the numeric values of the different tests. (CTE $=$ chronic toxic encephalopathy, NS = not significant).

\begin{tabular}{|c|c|c|c|c|c|c|c|c|c|}
\hline \multirow[t]{3}{*}{ Otoneurologic test } & \multirow{3}{*}{$\begin{array}{c}\begin{array}{c}\text { Results of } \\
\text { reference } \\
\text { group }\end{array} \\
\begin{array}{c}\text { Number of } \\
\text { persons with } \\
\text { significant } \\
\text { pathologyc }\end{array}\end{array}$} & \multicolumn{2}{|c|}{$\begin{array}{l}\text { Results of reference } \\
\text { group versus results } \\
\text { of solvent group }\end{array}$} & \multicolumn{6}{|c|}{$\begin{array}{l}\text { Results of reference group versus results of groups of different } \\
\text { clinical diagnosis }\end{array}$} \\
\hline & & \multirow{2}{*}{$\begin{array}{l}\text { Number } \\
\text { of patients } \\
\text { with } \\
\text { significant } \\
\text { pathologyc }\end{array}$} & \multirow[t]{2}{*}{ P-value } & \multicolumn{2}{|c|}{ Non-CTE } & \multicolumn{2}{|c|}{ Incipient CTEe } & \multicolumn{2}{|c|}{ CTE' } \\
\hline & & & & $\begin{array}{l}\text { Number } \\
\text { of patients } \\
\text { with } \\
\text { significant } \\
\text { pathologyc }\end{array}$ & P-value & $\begin{array}{l}\text { Number } \\
\text { of patients } \\
\text { with } \\
\text { significant } \\
\text { pathologyc }\end{array}$ & P-value & $\begin{array}{l}\text { Number } \\
\text { of patients } \\
\text { with } \\
\text { significant } \\
\text { pathologyc }\end{array}$ & P-value \\
\hline Saccade latency & 1 & 14 & $\leq 0.05$ & 3 & NS & 5 & $\leq 0.01$ & 6 & $\leq 0.05$ \\
\hline Saccade velocity & - & - & NS & - & NS & - & NS & - & NS \\
\hline \multicolumn{10}{|l|}{ Smooth pursuit (SP) } \\
\hline $\begin{array}{l}\text { SP } 50 \text { (gain) }^{g} \\
\text { SP } 51 \text { (gain)g }^{g} \\
\text { SP } 56 \text { (gain) }^{9}\end{array}$ & - & $\begin{array}{r}3 \\
1 \\
-\end{array}$ & $\begin{array}{l}\text { NS } \\
\text { NS } \\
\text { NS }\end{array}$ & $\frac{1}{-}$ & $\begin{array}{l}\text { NS } \\
\text { NS } \\
\text { NS }\end{array}$ & $\frac{1}{-}$ & $\begin{array}{l}\text { NS } \\
\text { NS } \\
\text { NS }\end{array}$ & $\begin{array}{r}1 \\
1 \\
-\end{array}$ & $\begin{array}{l}\text { NS } \\
\text { NS } \\
\text { NS }\end{array}$ \\
\hline \multicolumn{10}{|l|}{ Visual suppression (VS) } \\
\hline $\begin{array}{l}\text { VS } 30{\text { (gain })^{g}}^{\mathrm{V}} \\
\text { VS } 35 \text { (gain) }^{\mathrm{g}}\end{array}$ & $\overline{-}$ & $\begin{array}{r}7 \\
17\end{array}$ & $\begin{array}{l}\leq 0.001 \\
\leq 0.001\end{array}$ & $\begin{array}{l}1 \\
3\end{array}$ & $\begin{array}{l}\leq 0.001 \\
\leq 0.01\end{array}$ & $\begin{array}{r}4 \\
10\end{array}$ & $\begin{array}{l}\leq 0.001 \\
\leq 0.001\end{array}$ & $\begin{array}{l}2 \\
4\end{array}$ & $\begin{array}{l}\leq 0.001 \\
\leq 0.01\end{array}$ \\
\hline \multicolumn{10}{|c|}{ Sensory organization (SO) } \\
\hline $\begin{array}{l}\text { SO } 4^{9} \\
\text { SO } 5^{9} \\
\text { SO } 6^{9}\end{array}$ & $\overline{1}$ & $\begin{array}{r}13 \\
16 \\
7\end{array}$ & $\begin{array}{l}\leq 0.01 \\
\leq 0.05 \\
\text { NS }\end{array}$ & $\begin{array}{l}5 \\
6 \\
3\end{array}$ & $\begin{array}{l}\leq 0.05 \\
\text { NS } \\
\text { NS }\end{array}$ & $\begin{array}{l}3 \\
5 \\
1\end{array}$ & $\begin{array}{l}\leq 0.01 \\
\leq 0.05 \\
\quad \text { NS }\end{array}$ & $\begin{array}{l}5 \\
5 \\
3\end{array}$ & $\begin{array}{l}\leq 0.01 \\
\text { NS } \\
\text { NS }\end{array}$ \\
\hline \multicolumn{10}{|l|}{ Movement coordination } \\
\hline $\begin{array}{l}\text { Forward medium } \\
\text { Forward large } \\
\text { Backward medium } \\
\text { Backward large }\end{array}$ & $\frac{-}{-}$ & $\begin{array}{r}5 \\
5 \\
8 \\
13\end{array}$ & $\begin{aligned} & N S \\
\leq & 0.05 \\
\leq & 0.01 \\
\leq & 0.01\end{aligned}$ & $\begin{array}{l}1 \\
1 \\
1 \\
3\end{array}$ & $\begin{aligned} & N S \\
& N S \\
& N S \\
& \leq 0.05\end{aligned}$ & $\begin{array}{l}3 \\
2 \\
5 \\
7\end{array}$ & $\begin{aligned} & N S \\
\leq & 0.05 \\
\leq & 0.05 \\
\leq & 0.01\end{aligned}$ & $\begin{array}{l}1 \\
2 \\
2 \\
3\end{array}$ & $\begin{aligned} & N S \\
& \leq 0.05 \\
& \leq 0.01 \\
& \leq 0.01\end{aligned}$ \\
\hline
\end{tabular}

a $N=27$; mean age $45(S D 11)$ years, except for sensory organization and movement coordination ( $N=23$ ); mean age $=51$ (SD 11) years.

b $\mathrm{N}=60$, mean age $=48(\mathrm{SD} 10)$ years.

SD 2 of mean values of the referents.

$N=19$, mean age $=44(S D 10)$ years.

\& $N=21$, mean age $=50$ (SD 9) years.

$N=20$, mean age $=48(S D 9)$ years

9 See the methods section for an explanation of the variables. 
saccade was prolonged (but not the velocity and accuracy of the saccades) and the visual suppression ability of the vestibuloocular reflex was reduced (expressed as higher gain values) at increased frequencies in the solvent group when compared with the reference group. Data from 1 of the visual suppression tests (visual suppression tests 35 ) are illustrated in figure 3.

In dynamic posturography the sensory organization tests revealed larger sway patterns (expressed as lower scores) for the solvent group than for the reference group (table 2 and figure 2). Seven workers showed pathological results in all 3 tests. In the movement coordination test a longer reaction time was found in the solvent group than in the reference group (table 2 and figure 1). Twenty workers presented pathological results, 3 of them on all the tests, 2 of them on the forward medium and large

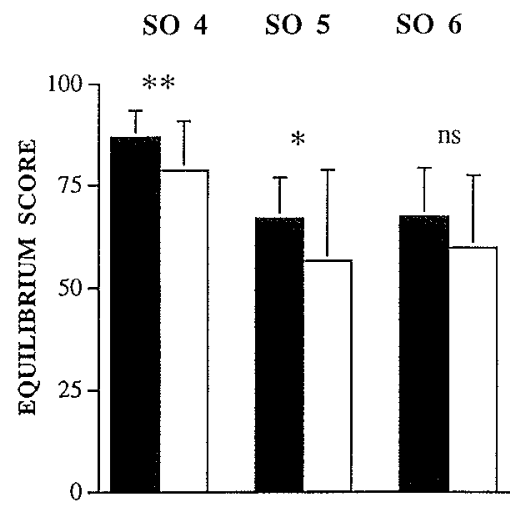

Figure 2. Dynamic posturography: mean equilibrium score +1 SD as the percentage of optimal stability tested on a sway referenced platform with the eyes open [sensory organization (SO) 4] and the eyes closed (SO 5) and on a sway-referenced platform with a sway referenced visual surrounding (SO 6). ( $=$ reference group, $N=23 ; \square=$ solvent group, $\left.N=60 ;{ }^{*} P \leq 0.05 ;{ }^{* *} P \leq 0.01\right)$

Visual suppression (VS 35)

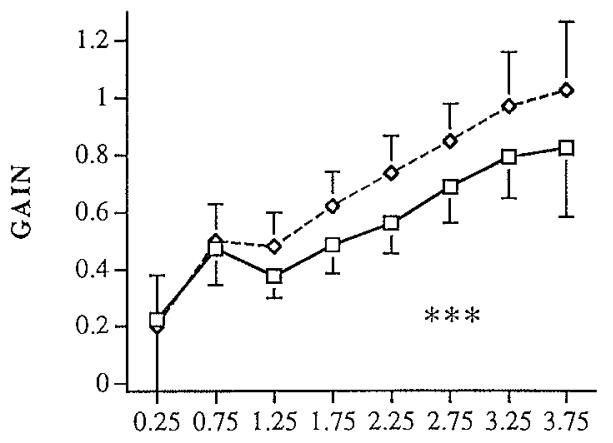

$\mathrm{Hz}$

Figure 3. Results of the visual suppression test. Mean gain $\pm 1 S D$ of eye movements as a function of a pseudorandomized sinusoidal frequency sweep $(0.25-3.75 \mathrm{~Hz})$ of the chair. The subjects fixated on a dot on the frame mechanically fixed to the chair (VS = visual suppression; $\square=$ reference group, $\mathrm{N}=27 ; \diamond=$ solvent group, $\mathrm{N}=60 ;{ }^{* \star *} \mathrm{P} \leq 0.001$ ) movement coordination tests, and 5 of them on the backward medium and large movement coordination tests.

There were no significant differences (ANOVA) between the special otoneurological numeric test values within the solvent group on one hand and the intensity and the duration of exposure, the psychometric evaluation and the clinical diagnosis on the other. An increased duration of exposure was however significantly correlated with a lowered capacity to follow a moving object in 2 of the smooth pursuit tests (smooth pursuit test 51 and smooth pursuit test 56) $(\mathrm{P} \leq 0.01$ and $\mathrm{P} \leq 0.05$, respectively) and prolonged reaction time in 1 of the movement coordination tests (large backward movement) ( $\mathrm{P} \leq 0.01)$ (figure 1). No other correlations were found.

The correlation between the special otoneurological numeric test values and the different psychometric tests of the solvent group were analyzed using the Spearman partial rank correlation. The results are illustrated in table 3 . It can be seen that there is a correlation between the smooth pursuit and sensory organization test results and several of the psychometric test results.

\section{Discussion}

The otoneurological investigation included an analysis of the vestibular and optoocular motor reflex system and also the postural control system. The function of the vestibular and optoocular motor reflex system is to maintain a steady view of the environment on the retina during movements of the head or the environment. Stimulation of the vestibular part of the vestibular and optoocular motor reflex system is elicited by the labyrinths. Impulses from the vestibular organs reach the eye muscles via the vestibular and oculomotor nuclei in the vestibuloocular motor reflex (VOR). Stimulation of the visual part of the vestibular and optoocular motor reflex system is elicited by a retinal signal. Such signals develop when the environment is moving (the optokinetic reflex), when the subject looks at a slowly moving target (the smooth pursuit, smooth pursuit tests) or when the vestibuloocular reflex elicits incomplete or erroneous eye movements during simultaneous movements of the head and environment (visual suppression, visual suppression tests). The retinal signals are conveyed to the vestibular nuclei in the brainstem via polysynaptic pathways. Fast eye movements (saccades) are generated in a region probably located primarily in the brainstem. Voluntary saccades are elicited when the subject shifts the gaze from 1 target of interest to another. The vestibular, the retinal, and the saccade signals are integrated in a structure located close to the vestibular nuclei. There is a strong connection between the cerebellum and the vestibular nuclei. The postural control is influenced by the vestibular and optoocular motor reflex system through vestibu- 
Table 3. Correlation between the psychometric and otoneurological test results. Correlation coefficient ( $r$ ) and value of significance $(P)$ are shown. (NS = not significant)

\begin{tabular}{|c|c|c|c|c|c|c|c|c|c|c|}
\hline & \multicolumn{4}{|c|}{ Perceptual accuracy and speed } & \multirow{2}{*}{\multicolumn{2}{|c|}{$\frac{\text { Memory }}{\begin{array}{c}\text { Benton visual } \\
\text { retention }\end{array}}$}} & \multirow{3}{*}{$\frac{\text { Psychomotor }}{\text { Cylinders }}$} & \multicolumn{3}{|c|}{ Cognitive } \\
\hline & \multicolumn{2}{|c|}{ Dots } & \multirow[t]{2}{*}{$\begin{array}{c}\text { Digit } \\
\text { symbols }\end{array}$} & \multirow[t]{2}{*}{$\begin{array}{l}\text { Identical } \\
\text { numbềs }\end{array}$} & & & & \multirow[t]{2}{*}{ Synonyms } & \multirow{2}{*}{$\begin{array}{c}\text { Figure } \\
\text { classi- } \\
\text { fication }\end{array}$} & \multirow[t]{2}{*}{$\begin{array}{l}\text { Block } \\
\text { design }\end{array}$} \\
\hline & Accuracy & Speed & & & Correct & Error & & & & \\
\hline Saccade latency (SD) & NS & $\begin{array}{l}r=0.32 \\
P \leq 0.05\end{array}$ & NS & NS & NS & NS & NS & NS & NS & NS \\
\hline \multicolumn{11}{|l|}{ Smooth pursuit (SP) } \\
\hline SP 50 & NS & $\begin{array}{l}0.29 \leq r \leq 0.34 \\
0.01 \leq P \leq 0.05\end{array}$ & $\begin{aligned} 0.26 & \leq r \leq 0.46 \\
0.001 & \leq P \leq 0.05\end{aligned}$ & NS & NS - & \multirow{3}{*}{$\begin{aligned} &-0.31 \leq r \leq-0.27 \\
& P \leq 0.05 \\
&-0.32 \leq r \leq-0.26 \\
& P \leq 0.05 \\
& \text { NS }\end{aligned}$} & 7 NS & NS & NS & NS \\
\hline SP 51 & NS & $\begin{array}{c}0.26 \leq r \leq 0.32 \\
P \leq 0.05\end{array}$ & $\begin{aligned} 0.27 & \leq r \leq 0.30 \\
P & \leq 0.05\end{aligned}$ & NS & NS - & & 6 NS & NS & NS & NS \\
\hline SP 56 & $\begin{array}{l}0.28 \leq r \leq 0.34 \\
0.01 \leq P \leq 0.05\end{array}$ & $\begin{array}{c}0.26 \leq r \leq 0.29 \\
P \leq 0.05\end{array}$ & $\begin{array}{c}0.30 \leq r \leq 0.33 \\
P \leq 0.05\end{array}$ & NS & NS & & NS & NS & NS & NS \\
\hline \multicolumn{11}{|l|}{ Visual suppression (VS) } \\
\hline $\begin{array}{l}\text { VS } 30 \\
\text { VS } 35\end{array}$ & $\begin{array}{l}\text { NS } \\
\text { NS }\end{array}$ & $\begin{array}{l}\text { NS } \\
\text { NS }\end{array}$ & $\begin{array}{l}\text { NS } \\
\text { NS }\end{array}$ & $\begin{array}{l}\text { NS } \\
\text { NS }\end{array}$ & $\begin{array}{l}\text { NS } \\
\text { NS }\end{array}$ & $\begin{array}{l}\text { NS } \\
\text { NS }\end{array}$ & $\begin{array}{l}\text { NS } \\
\text { NS }\end{array}$ & $\begin{array}{l}\text { NS } \\
\text { NS }\end{array}$ & $\begin{array}{l}\text { NS } \\
\text { NS }\end{array}$ & $\begin{array}{l}\text { NS } \\
\text { NS }\end{array}$ \\
\hline \multicolumn{11}{|c|}{ Sensory organization (SO) } \\
\hline SO 4 & NS & \multirow{2}{*}{$\begin{array}{l}r=0.27 \\
P \leq 0.05 \\
r=0.28 \\
P \leq 0.05\end{array}$} & \multirow{2}{*}{$\begin{array}{c}r=0.31 \\
P \leq 0.05 \\
N S\end{array}$} & NS & \multirow{2}{*}{$\begin{array}{c}r=0.29 \\
P \leq 0.05 \\
N S\end{array}$} & \multirow{2}{*}{$\begin{array}{c}r=0.35 \\
P \leq 0.01 \\
N S\end{array}$} & NS & NS & \multirow{2}{*}{$\begin{array}{l}r=0.30 \\
P \leq 0.05 \\
\quad N S\end{array}$} & NS \\
\hline So 5 & NS & & & NS & & & NS & NS & & NS \\
\hline $\begin{array}{l}\text { So } 6 \\
\text { Movement coordinatio }\end{array}$ & NS & NS & NS & NS & NS & NS & NS & NS & NS & NS \\
\hline Forward & NS & NS & NS & NS & NS & NS & NS & NS & NS & NS \\
\hline Backward & NS & NS & NS & NS & NS & NS & NS & NS & NS & NS \\
\hline
\end{tabular}

lar and ocular spinal reflex systems including brainstemcerebellar connections $(14,15)$.

The otoneurological findings of the solvent group showed a high degree of caloric hyperreactivity and square waves, a prolonged latency of the fast voluntary eye movement, a reduced visual suppression ability and pathology in the dynamic posturography tests when compared with the corresponding results of the reference group. These findings confirm previous reports (4-9, $13,16)$. They indicate lesions primarily in basic reflexes of the brainstem and cerebellum (17-20). To some extent these neurophysiological indications of the location of the lesions are supported by structural findings in magnetic resonance imaging patients with chronic toxic encephalopathy and autopsy results of toluene abusers $(21-24)$.

The correlation between the otoneurological test results in the present study and the history of exposure was poor. There was a significant group correlation between some of the test results and the duration of exposure (figure 1). However, the increasing duration of exposure with increasing age of the subject may have contributed to this significance. There are several reasonable explanations for the poor correlation. The intensity of exposure is very difficult to evaluate, and therefore the degree of approximation is high. Exposure sometimes included a variety of different solvents, and the individual toxicity may have differed quantitatively and qualitatively. Such differences in the vestibular and optoocular motor reflex system have been observed in rats acutely exposed to different aromatic and aliphatic hydrocarbons (2). Vary- ing regional morphological alterations of glia cells and neuronal cells in long-term exposed animals have been found for different solvents (25), and therefore different mechanisms of action are possible. The sensitivity of the equilibrium system to solvents may also be related to factors other than duration, intensity, and type of solvent exposure, as, for instance, to hereditary factors and combination with other conditions.

Even though otoneurological tests primarily involve basic reflexes, the results are surely dependent on activities in many regions of the central nervous system, such as the reticular formation and the subcortical and cortical regions $(14,15,26)$. It is thus not surprising that psychometric test results, which are sensitive to diffuse organic brain damage $(11,27)$, correlate with some otoneurological test results. We have demonstrated that the saccade and the smooth pursuit test results, as well as those of the sensory organization 4 test of the posturography, were significantly related to behavioral test results concerning memory and perceptual skills (table 3 ). These tests refer to problems of attention, which may also influence some otoneurological tests.

On the other hand, the visual suppression tests and the movement coordination tests in the posturography, which are significantly impaired in workers exposed to solvents, did not seem to be related to any of the psychometric test modalities. Evidently these otoneurological tests do not reveal the same disturbances in the central nervous system that psychometric tests do.

It is well known that patients with diseases that give otoneurological test results similar to those described in 
this report complain of a sensation of unsteadiness in everyday situations, which may sometimes be disabling (14). The same symptoms are described by workers exposed to solvents $(28,29)$. The deficits in the central nervous system, confirmed by the present investigation, thus seem to be relevant to the subjective symptoms experienced by long-term solvent-exposed people.

Regarding chronic toxic encephalopathy, the final diagnosis in the group of men exposed to solvents in our study did not correlate with the otoneurological findings. Even in the nonchronic toxic encephalopathy group there were many persons with disturbances in the equilibrium tests. This discrepancy can be explained by the fact that the psychometric test results had a high degree of significance for the diagnosis of chronic toxic encephalopathy. Even though there may be some overlapping, the psychometric tests do not reflect the same functions of the central nervous system as otoneurological investigations do. Furthermore, solvents should not be considered one entity; individual solvents may affect different functions and structures of the central nervous system.

It has previously been proposed that impairment of the vestibulocerebellar system, revealed by otoneurological tests, should be included in the diagnosis of chronic toxic encephalopathy (30). At least the results of the present, and also previous reports $(5-9,13,16)$, imply that the investigation of people exposed to solvents should include otoneurological tests if unsteadiness is described by the subjects. These tests may contribute to balanced information on different disturbances in the central nervous system after long-term exposure to solvents.

\section{Acknowledgments}

This investigation was supported by a program project from the Swedish Work and Environment Fund, grant $84-1291$.

The authors thank the vestibular assistent Lisbeth Noaksson and engineer Johan Deblén for their skillful assistance.

\section{References}

1. Axelsson $O$, Hogstedt $C$. The health effects of solvents. In: Zenz C, Dickerson OB, Horvath EP, editors. Occupational medicine, 3rd ed. St Louis (MI): Mosby-Year Book Inc, 1994; 764-78.

2. Niklasson M, Tham R, Larsby B, Eriksson B. Effects of toluene, styrene, trichloroethylene, and trichloroethane on the vestibulo- and opto-oculo motor system in rats. Neurotoxicol Teratol 1993;15:327-34.
3. Nylén P, Larsby B, Johnson AC, Eriksson B, Höglund G, Tham R. Vestibulo-oculomotor, optooculomotor and visual function in the rat after long-term inhalation exposure to toluene. Acta Otolaryngol (Stockh) 1991;111:36-43.

4. Hydén D, Larsby B, Andersson H, Ödkvist LM, Liedgren SRC, Tham R. Impairment of visuo-vestibular interaction in humans exposed to toluene. ORL J Otorhinolaryngol Relat Spec 1983;45:262-9.

5. Ödkvist LM, Arlinger SD, Edling C, Larsby B, Bergholtz LM. Audiological and vestibulo-oculomotor findings in workers exposed to solvents and jet fuel. Scand Audiol 1987;16:7581.

6. Möller C, Ödkvist LM, Thell J, Larsby B, Hydén D, Bergholtz LM, et al. Otoneurological findings in psycho-organic syndrome caused by industrial solvent exposure. Acta Otolaryngol (Stockh) 1989;107:5-12.

7. Möller C, Ödkvist L, Larsby B, Tham R, Ledin T, Bergholtz L. Otoneurological findings in workers exposed to styrene. Scand J Work Environ Health 1990;16:189—94.

8. Pollastrini L, Abramo A, Cristalli G, Baretti F, Greco A. Studio dei segni precoci di ototossicità professionale da inalazione di solventi industriali derivati dal benzene [Otoneurological and audiological findings in workers exposed to industrial solvents]. Acta Otorhinol Ital 1994;14:503 -12. English summary.

9. Calabrese G, Martini A, Sessa G, Cellini M, Bartolucci, Marcuzzo $\mathrm{G}$, et al. Otoneurological study in workers exposed to styrene in the fiberglass industry. Int Arch Occup Environ Health 1996;68:219-23.

10. Ekberg $\mathrm{K}$, Hane $\mathrm{M}$. Test battery for investigating functional disorders - the TUFF battery. Scand J Work Environ Health 1984;10 suppl 1:14 7 .

11. Ekberg K, Hane M, Berggren T. Psychologic effects of exposure to solvents and other neurotoxic agents in the work environment. In: Zenz C, Dickerson OB, Horvath EP, editors. Occupational medicine, 3rd ed. St Louis (MI): Mosby-Year Book Inc, 1994:779- 89 .

12. Flodin U, Edling C, Axelsson O. Clinical studies of psychoorganic syndromes among workers with exposure to solvents. Am J Ind Med 1984;5;287-95.

13. Ledin T, Jansson E, Möller C, Ödkvist LM. Chronic toxic encephalopathy investigated using dynamic posturography. Am J Otolaryngol 1991;12:96-100.

14. Baloh RW, Honrubia V. Clinical neurophysiology of the vestibular system, 2nd ed. Philadelphia (PA): FA Davis 1990:3111.

15. Büttner U, Büttner-Ennever JA, Present concepts of oculomotor organization. In: Büttner-Ennever JA, editor. Neuroanatomy of the oculomotor system: reviews of oculomotor research, vol 2. Amsterdam: Elsevier 1988:3--32.

16. Kelafant GA, Berg RA, Schleenbaker R. Toxic encephalopathy due to 1,1,1-trichloroethane exposure. Am J Ind Med 1994;25:439-46.

17. Dichgans J, von Reutern GM, Römmelt U. Impaired suppression of vestibular nystagmus by fixation in cerebellar and noncerebellar patients. Arch Psychiatr Nervenkr 1978;226: 183-99.

18. Baloh RW, Honrubia VH, Sills A. Eye-tracking and optokinetic nystagmus: results of quantiative testing in patients with well-defined nervous system lesions. Ann Otol Rhinol Laryngol 1977;83:108-14.

19. Möller C, Aita J, Smith S, White V, Ödkvist LM, Cyr D, et al. Otoneurological findings in olivo-ponto-cerebellar atrophy (OPCA): dysfunction and plasticity in otoneurology with em- 
phasis on the vestibular system [dissertation]. Linköping (Sweden): University Hospital, 1989.

20. Voorhees RL. Dynamic posturography findings in central nervous system disorders. Otolaryngol Head Neck Surg 1990; 103:96-101.

21. Yamanouchi N, Okada S-I, Kodama K, Hirai S, Sekine H, Murakami A, et al. White matter changes caused by chronic solvent abuse. Am J Neuroradiol 1995;16:1643 —9.

22. Thoumas K- $\AA$, Möller C, Ödkvist LM, Flodin U, Dige N. MRI in solvent induced chronic toxic encephalopathy. Acta Radiol 1996;37:177-9.

23. Rosenberg NL, Kleinschmidt-DeMasters BK, Davis KA, Dreisbach JN, Hormes JT, Filley CM. Toluene abuse causes diffuse central nervous system white matter changes. Ann Neurol 1988;23:611-4.

24. Escobar A, Aruffo C. Chronic thinner intoxication: clinico pathologic report of a human case. J Neurol Neurosurg Psychiatry 1980;43:986-94.
25. Arlien-Søborg P, editor. Solvent neurotoxicity. Boca Raton (FL): CRC Press 1992.

26. Leigh J, Zee D. The neurology of eye movements. Philadelphia (PA): FA Davis Co, 1991.

27. World Health Organization (WHO). Organic solvents and the central nervous system. Copenhagen: WHO, 1985. Environmental health 5 .

28. Hein HO, Suadicani P, Gyntelberg F. Mixed solvent exposure and cerebral symptoms among active and retired workers: an epidemiological of 3,387 men aged 53-75 years. Acta Neurol Scand 1990;81:97-102.

29. Juntunen J. Neurotoxic syndromes and occupational exposures to solvents. Environ Res 1993;60:98-111.

30. Gilioli R. Euronest: a concerted action of the European community for the study of organic solvent neurotoxity. Environ Res 1993;62:89-98

Received for publication: 11 October 1996 